\title{
Correlating spiritual and emotional intelligence with academic performance among Pakistani students
}

\author{
Jamshid Ali Turi' ${ }^{1}$, Anita Abdul Rani' ${ }^{2}$ Imaduddin Abidin ${ }^{3}$, Fatimah Mahmud ${ }^{4}$, Alaeldeen Al Adresi ${ }^{5}$ \\ ${ }^{1}$ Department of Management Sciences, SZABIST Larkana Campus, Pakistan \\ ${ }^{2,3}$ Centre of Modern Languages and Human Sciences, University Malaysia Pahang, Malaysia \\ ${ }^{4,5}$ Faculty of Industrial Management, University Malaysia Pahang, Malaysia
}

\begin{tabular}{l} 
Article Info \\
\hline Article history: \\
Received Jan 14, 2020 \\
Revised Mar 30, 2020 \\
Accepted Apr 28, 2020 \\
\hline
\end{tabular}

\section{Keywords:}

Academic performance

Emotional intelligence

Pakistan

Spiritual intelligence

\begin{abstract}
Continuous learning works like a blood for organization and individuals to proceed and succeed. Underdeveloped countries need to address their academic issues. Academic prosperity is linked to economy and technology disruptions so it's an important element to bring underdeveloped countries up to the mark to thrive and survive in this technical era. Academic prosperity depends upon student's enthusiastic attitude and their emotional and spiritual intelligences. This study was conducted in learning organizations to see the impact of emotional and spiritual intelligences on academic performance. Population of the study is the academic institutes of Pakistan. Data were collected using cross-sectional questionnaire-based survey from 113 students in Pakistan. The findings provide positive and significant correlations among the types of intelligences and academic performance. Data was analyzed using SPSS and the results were verified using statistical methods like correlation, regression, ANNOVA, Cronbach alpha and means. This study highlights the role of emotional intelligence and spiritual intelligence on academic performance and found out that it has the most demanding and significant effect on the academic performance, therefore it needs better integration in academic practices, routine and culture.
\end{abstract}

This is an open access article under the CC BY-SA license.

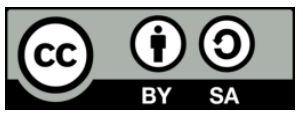

Corresponding Author:

Jamshid Ali Turi,

Department of Management Sciences,

SZABIST Larkana Campus,

Larkana, Pakistan.

Email: Jamshidturi@gmail.com

\section{INTRODUCTION}

Organizations in 21 st centuries are facing complexity and uncertainty due to globalization, knowledge economy and technology disruption [1]. One appropriate way to cope with these challenges is continuous learning, which equips organizations and individuals to survive, innovate and lead at global frontiers besides maintaining their competitive edge. Academic performance focus on academic problems' solution, creation of new opportunities, developing new insight, synergizing and charging work environment socially and emotionally, enhancing performance and bringing cognitive, behavioral and social productive changes to organizations and its students. Academic prosperity is directly linked to the employment of the country. Emotional intelligence can affect academic performance. Though emotional intelligence has been linked to the academic performance but not academic prosperity. Among many new learning stimuli, Emotional Intelligence (EQ) and Spiritual Intelligence (SQ) have been proven as a good instinct for learning, creating motivations, agility, curiosity and enthusiasm in learning entity $[2,3]$. Though the impact of emotional and spiritual intelligence has been studied on the resilience of the students but, the impact of these 
two variables hasn't been studied on the academic prosperity of the Pakistani students. Though some studies have identified the impact of emotional intelligence on academic performance but this still needs further exploration. As according to [4-6] if the students are emotionally unstable this can affect the students ability to understand lessons. Likewise Emotional intelligence is considered critical to academic success.

Being developing country this is very important that we should identify the factors that are important for the academic prosperity of the country. Pakistan is facing so many educational challenges that we need to address. As it can lead to sustained economic development we need to address the issues and elements linked with it. Academic prosperity is the most important aspect which needs further exploration. This research will provide a clear idea about the correlating relationship of emotional and spiritual intelligence on academic performance. Learning organizations have the hallmark of exploring and exploiting new phenomenon and emotional intelligence and spiritual intelligence are the forces for delivering the best suitable, optimal, economical and feasible results to promote academic performance, productivity, efficiency and effectiveness. Therefore, this research was conducted in the public and private universities of Pakistan. Therefore, a large-scale empirical study is needed to demonstrate the relationship between intelligences and academic performance in education sector.

The main objectives of the research is to investigate the impact of EQ and SQ on academic performance as recommended by different researchers [7,8]. Beside modern teaching methodologies and techniques, emotional and spiritual intelligence are the most requisite tools to educate the students in best possible and suitable ways. Emotional and spiritual intelligence charge the environment socially, emotionally, ethically and psychologically. Motivates the learner intrinsically and boost the teaching learning processes. Emotional Intelligence has a century backed history and can be found in the work of Aristotle and other different researchers. It is defined as the ability to recognize the emotions of self and others it helps the person to respond accordingly [9, 10]. Jafari [4], Hatami [5], and Rajeswari [11] also explained emotional intelligence in his social intelligence theory by stating that it is the way to understand, accept and react wisely to the emotions of all human beings that may be man, woman, boy or girl [12]. Similarly, spiritual intelligence, leads the learner towards self-actualization, helps them to explore learner hidden and inner capacities and capabilities. Spiritual and emotional intelligence are being used for behavior modifications and inner-self engineering [13, 14].

Emotional Intelligence (EQ) was introduced with intensity and application in the writing of Goleman in his best-selling book "Emotional Intelligence Why It Can Matter More Than IQ" in 1995. It is defined as the ability to recognize the emotions of self and other and respond them accordingly $[4,11]$. It is considerd as a predictor, a pre-requisite of academic performance as it develops intrinsic motivations among the students of all age, gender, color and cost for both short and long-term achievements [15, 16]. It has equal applications at all levels for academic performance and personality development [11]. Farhan and Usman [17] concluded that EQ has indirect effect on academic performance through the mediating role of self-efficacy which further increases learning performance. It promotes intrapersonal skills focuses on inner hidden skills, thoughts, strength and potentials and leads them to self-actualization phase. It helps in recognizing person's own-self, their strengths and weaknesses, moods and emotions and their impacts on others $[18,19]$. It improves decision making skills. Through intrapersonal skills person controls his thoughts and actions, remains motivated, calm and confident and starts believing in himself, both consciously and subconsciously, which increases productivity and performance [5]. Jiang et al. [20] stated that with high intra-personal skills and self-awareness intrinsic motivations are created which lead to high learning achievements. Beside this, it improves learning strategies, memorization and cognition abilities [4]. Emotional Intelligence regulates studies, Cross-cultural, create empathetic and socio-emotionally charged environment. One of the core areas of EQ is the creation of the social skills, which prepare learner to use learning skills and facilitate social behaviors and improve academic performance [21, 22]. In research findings, it has been found that, it promotes positive moods in learner, which helps in solving complex cognitive problems, has facilitating impact on memory, create confidence and smoothen learning and decision-making processes [5, 23]. EQ better equips learner with stress management strategies and makes him/her adoptable, adaptable and manageable and he starts enjoying the patterns of life, concentrate on him/her, starts moving towards self-actualization.

H1: Emotional Intelligence significantly effects academic performance.

Spiritual intelligence (SQ) can be defined as the capacity of mind to handle substantial and spiritual aspects of personal and professional life. It carries meaning, purpose, potential, philosophy, integrity and an enthusiastic phenomenon for human personal, social and academic life [24]. It develops sacred holism among students, explores its hidden potentials which boost academic productivity, performance and brings continuous learning, transformational change and improvement to organization [25, 26]. It transforms students and organization as an adoptive system. Makes the person spontaneous, compassionate, competitive and resilience; develops positive interactive culture, integrated positive workforce, sense of community and

Correlating spiritual and emotional intelligence with academic performance among ... (Jamshid Ali Turi) 
continuous learning among workforce [2, 27]. Citizenship behaviors are developed among students, who accept academic norms and values and tries to promote them [28, 29]. It empowers students, develop their confidence, lead them towards self-development and self-actualization, polish their skill, give them integrity, harmony, enthusiasm, direction, new philosophy of life and keep them healthy mentally and physically [20, 30]. A recent study by Martynowska [31] on students' psychological wellbeing in Catholic university in Poland shows that students' SQ enhances their emotions, relationship with other and shows a positive behavior. SQ increases as they become calmer, patient, motivated. They start focusing on academic affairs and researchers. It encourages educators to emphasize in SQ as a way to approach students. All above mentioned arguments explain that spiritual intelligence has intrinsic motivation and plays critical role in developing and learning domain. In modern teaching and learning techniques, emotional and spiritual intelligence are not given its due weightage. They are ignored and have not been considered as pre-requisite for the teaching learning processes. After carefully analyzing various research studies on EQ and SQ, this study aimed at introducing the concept of using students to measure both variables and their impact on academic achievement.

\section{RESEARCH METHOD}

This study is based on the primary data collected through self-administered questionnaire from the teaching faculty and general management of higher education 21 Higher Education Commission (HEC) recognized institutions/universities operating in Rawalpindi and Islamabad region of Pakistan. The aim of the study was to explore the relationship among EQ and SQ and their impact on academic performance. Stratified random sampling sampling (Non-probability) technique is adopted for the present study which is commonly practiced in the field of social sciences [20,32]. A questionnaire from previous studies was adopted to get the objectives of the study $[20,21,30]$. Data about all the main variables of the study/research was collected from the target population. The questionnaire is based on a five-point Likert scale starting from 1 representing "Strongly disagree" to 5 with "Strongly agree" option.

The questionnaire is composed of two parts. Section first covers the demographic and personal characteristics of the population containing 6 questions and the second part contained questions about independent and dependent variables. Data was attained from the public and private universities students in capital city Islamabad, Pakistan. Total of 113 students participated in the study.

\section{RESULTS AND DISCUSSION}

\subsection{Reliability analysis}

Reliability Analysis Reliability analysis allows you to study the properties of measurement scales and the items that compose the scales. The reliability analysis procedure calculates a number of commonly used measures of scale reliability and also provides information about the relationships between individual items in the scale. In current study, after calculating the construct ability consistent results were attained. Internal consistency analysis was done separately for the variables corresponding to each of the constructs; over all reliability of the variables. Table 2 shows the values of Cronbach's coefficient, mean and variance, if we delete one item for example, Table 1 shows that if we delete the variable EQ i.e. then the overall value of Cronbach's alpha becomes .914 compared to .953 and it means that variables and questions selected in this research is a reliable measure and it should be considered in future research work. All the above variables have Cronbach's values in significant range ( 0.7 or above) which are acceptable $[7,20,33]$.

Table 1. Reliability statistics all constructs

\begin{tabular}{cc}
\hline Cronbach's Alpha & N of Items \\
\hline .953 & 58 \\
\hline
\end{tabular}

Table 2. Item-total statistics

\begin{tabular}{ccccc}
\hline & $\begin{array}{c}\text { Scale Mean if } \\
\text { Item Deleted }\end{array}$ & $\begin{array}{c}\text { Scale Variance } \\
\text { if Item Deleted }\end{array}$ & $\begin{array}{c}\text { Corrected Item- } \\
\text { Total Correlation }\end{array}$ & $\begin{array}{c}\text { Cronbach's Alpha } \\
\text { if Item Deleted }\end{array}$ \\
\hline EQ & 10.2286 & 3.215 & .675 & .914 \\
SQ & 10.3967 & 2.729 & .874 & .845 \\
AP & 10.3698 & 2.809 & .807 & .869 \\
\hline
\end{tabular}

Int. J. Eval. \& Res. Educ. Vol. 9, No. 2, June 2020: 278 - 284 


\subsection{Descriptive statistics}

Descriptive statistics deals with the concepts and methods concerned with summarization and explanation of the important aspects of the statistical data. Means and standard deviation was calculated to check the consistency among the research variable. The mean values of the Table 3 are near to maximum values and the values of the standard deviation are very low, which means that emotional and spiritual intelligence have positive role and greater impact on academic performance according to the perception of the students.

Table 3. Descriptive statistics of the questionnaire

\begin{tabular}{cccccc}
\hline & $\begin{array}{c}\text { Number of } \\
\text { respondents }\end{array}$ & Minimum & Maximum & Mean & $\begin{array}{c}\text { Std. } \\
\text { Deviation }\end{array}$ \\
\hline EQ & 113 & 1.83 & 4.75 & 3.6246 & .57089 \\
SQ & 113 & 1.33 & 4.50 & 3.4564 & .62495 \\
AP & 113 & 1.77 & 4.71 & 3.4834 & .63340 \\
Valid N & 113 & & & & \\
\hline
\end{tabular}

\subsubsection{Inferential statistics}

Table 4 shows the relationship between dependent and independent variables. There are 113 respondents that shows, independent variable (EQ) has moderately significant relationship with academic performance (AP) where $(\mathrm{r}=.600)$. The other independent variable academic elements have significant relationship with academic performance where $(\mathrm{r}=.763)$. The third independent variable knowledge has strong significant relationship with academic performance where $(r=.786)$. The correlation table show the significance relationship among the elements of the intelligence and exhibit that each independent variable has significant relationship with the dependent variable, academic performance. This result is in line with EQ studies done by previous scholar [12, 20] and also parallel with SQ studies done by other researchers $[23,28]$.

Table 4. Relationship between variables

\begin{tabular}{|c|c|c|c|c|}
\hline & & EQ & SQ & $\mathrm{AP}$ \\
\hline \multirow{3}{*}{ EQ } & Pearson Correlation & 1 & & \\
\hline & Sig. (2-tailed) & & & \\
\hline & $\mathrm{N}$ & 113 & & \\
\hline \multirow{3}{*}{ SQ } & Pearson Correlation & $.573^{* *}$ & 1 & \\
\hline & Sig. (2-tailed) & .000 & & \\
\hline & $\mathrm{N}$ & 113 & 113 & \\
\hline \multirow{3}{*}{ AP } & Pearson Correlation & $.600^{* *}$ & $.763^{\text {** }}$ & 1 \\
\hline & Sig. (2-tailed) & .000 & .000 & \\
\hline & $\mathrm{N}$ & 113 & 113 & 113 \\
\hline
\end{tabular}

Regression analysis was run through SPSS and simple check the independent relationship with dependent. In the first step we used control variable impact on dependent variable and second step was independent variables. Table 5 shows that gender has positive impact on academic performance. Second step shows significant relationship between the independent variables (Emotional and Spiritual Intelligence) and dependent variable (Academic Performance). Emotional Intelligence significantly effects academic performance $(\mathrm{B}=.09,>.005)$ and spiritual Intelligence significantly effects academic performance $(\mathrm{B}=.34,>.005)$ are accepted.

Table 5. Regression analysis

\begin{tabular}{llc}
\hline \multicolumn{3}{c}{ Academic Performance } \\
\hline Step 1 & $B$ & $\Delta R^{2}$ \\
Gender & $.13^{* *}$ & $.07^{*}$ \\
& & \\
Step 2 & & \\
Emotional Intelligence & $.09^{*}$ & \\
Spiritual Intelligence & $.34^{* *}$ & $.66^{* *}$ \\
\hline
\end{tabular}




\subsection{Participants' demographic characteristics}

Significant difference is seen in EQ and SQ on AP the basis of gender on all constructs of the study. It means that EQ and SQ is different for male and female. It means that the level of emotional and spiritual intelligence is different for male and female according to the study results. Table 6 and Table 7 show the ANOVA for gender and the mean values for gender resepectively.

Table 6. ANOVA for gender

\begin{tabular}{|c|c|c|c|c|c|c|}
\hline & & $\begin{array}{r}\text { Sum of } \\
\text { Squares }\end{array}$ & Df & $\begin{array}{c}\text { Mean } \\
\text { Square }\end{array}$ & $\mathrm{F}$ & Sig. \\
\hline \multirow{3}{*}{$\mathrm{P}$} & Between Groups & 10.495 & 1 & 10.495 & 85.092 & .000 \\
\hline & Within Groups & 31.204 & 253 & .123 & & \\
\hline & Total & 41.699 & 254 & & & \\
\hline \multirow{3}{*}{ Q } & Between Groups & 7.612 & 1 & 7.612 & 28.159 & .000 \\
\hline & Within Groups & 68.394 & 253 & .270 & & \\
\hline & Total & 76.007 & 254 & & & \\
\hline \multirow{3}{*}{ Q } & Between Groups & 4.542 & 1 & 4.542 & 24.350 & .000 \\
\hline & Within Groups & 47.196 & 253 & .187 & & \\
\hline & Total & 51.738 & 254 & & & \\
\hline
\end{tabular}

Table 7. Mean values for gender

\begin{tabular}{cccc}
\hline \multicolumn{2}{c}{ Gender } & EQ & SQ \\
\hline Female & Mean & 3.5765 & 3.8869 \\
Male & Mean & 3.2213 & 3.6125 \\
Total & Mean & 3.3578 & 3.7180 \\
\hline
\end{tabular}

Mean comparison shows that female is having better "EQ" (Mean=3.57) and "SQ" $(M=3.88)$ skills as compared to male colleagues and overall, they are having better emotional and spiritual skills as manifested by the values to "EQ" $(M=3.22)$ and "SQ" $(M=3.61)$ respectively. To see the impact of EQ and SQ on AP based on Academic qualification, ANNOVA was used as shown in Table 8.

Table 8. ANOVA for qualification

\begin{tabular}{|c|c|c|c|c|c|c|}
\hline & & Sum of Squares & df & Mean Square & $\mathrm{F}$ & Sig. \\
\hline \multirow{3}{*}{ Academic Performance } & Between Groups & 8.664 & 2 & 4.332 & 33.046 & .000 \\
\hline & Within Groups & 33.035 & 252 & .131 & & \\
\hline & Total & 41.699 & 254 & & & \\
\hline \multirow{3}{*}{ EQ } & Between Groups & 5.879 & 2 & 2.940 & 10.564 & .000 \\
\hline & Within Groups & 70.127 & 252 & .278 & & \\
\hline & Total & 76.007 & 254 & & & \\
\hline \multirow{3}{*}{ SQ } & Between Groups & 3.934 & 2 & 1.967 & 10.370 & .000 \\
\hline & Within Groups & 47.804 & 252 & .190 & & \\
\hline & Total & 51.738 & 254 & & & \\
\hline
\end{tabular}

Significant difference is seen in the level of intelligences (EQ and SQ) on AP based on academic qualification. From the mean comparison Table 9, it is shown that $\mathrm{PhD}$ degree holders are having more Emotional intelligence and Spiritual intelligence skills than BS and MS degree holders. Therefore, they can perform better in their academic career and in practical lives as compared to BS and MS graduates.

Table 9. Means score for qualifications

\begin{tabular}{cccc}
\hline \multicolumn{2}{c}{ Program of Study } & EQ & SQ \\
\hline BS & Mean & 3.2118 & 3.5986 \\
MS & Mean & 3.5321 & 3.8608 \\
PhD & Mean & 3.5571 & 3.7980 \\
Total & Mean & 3.3578 & 3.7180 \\
\hline
\end{tabular}

As the results of the study approve that emotional and spiritual intelligence is directly related to the academic prosperity. Still due to the complexity, comprehensiveness and vagueness involved in these terms, further exploration is required. The results of the study are in line with the previous researches 
conducted in some other contexts which also evidence that Emotional intelligence is a significant element for the academic prosperity [18]. Emotional intelligence prioritizes thoughts and helps to regulate different situations which in turn helps in academic prosperity [23]. Likewise, if we talk about spiritual intelligence though it has not been directly linked to academic performance but previously it has been seen to effect employee's performance [23, 34]. There is no single optimum approach or contributing factor for academic performance. A variety of seen and unseen factors contribute to its development. Different kinds of approaches and systems need to be employed in organizations to effectively deal with the diversity of knowledge and attributes. But these social, psychological, motivational and emotional factors are the most demanding and have significant effect on academic performance; therefore, we need better integration in academic practices, routine and culture. Emotional and spiritual intelligence can be equally applicable to the vocational and technical education, as it moves, leads and intrinsically motivates learners to get engage in experiential learning and creative activities. As Kolb has stated in his experiential learning theory, learning needs intrinsic and extrinsic booster, which can be provided through emotional and spiritual intelligence.

Although the paper provides insight toward a new relationship that has not been studied before still there are a few limitations that can be addressed in future. Due to time limitation and limited resources data were only collected from 113 students. This can be elaborated in future by increasing sample size. Another limitation that can be addressed in future is that this research is conducted in contextual study of Pakistani institutes. In future these variables can be studied in different contextual settings.

\section{CONCLUSION}

This study finds out the role of emotional intelligence and Spiritual Intelligence on the academic performance. The findings revealed that there is positive relationship between emotional intelligence and academic performance. Emotional intelligence predicts students' academic achievement. The results clearly show that the selected constructs (emotional and spiritual intelligence) present a good measure for the academic performance construct. Universities should develop conducive environment for learning culture, where tacit and explicit knowledge can be assimilated. software can be installed for the said purpose to get interpreted and assimilated knowledge.

\section{ACKNOWLEDGEMENTS}

This study acknowledges the Universiti Malaysia Pahang for funding assistances under RDU 160368 Grant.

\section{REFERENCES}

[1] M. A. Preston, A. Kharrufa, and Z. Kong, "Making L2 learners' reasoning skills visible: The potential of Computer Supported Collaborative Learning Environments," Thinking Skills and Creativity, vol. 22, pp. 303-322, 2016.

[2] N. Pant and S. K. Srivastava, "The Impact of Spiritual Intelligence, Gender and Educational Background on Mental Health Among College Students," Journal of Religion and Health, vol. 58, pp. 87-108, 2019.

[3] C. Larmuseau, P. Desmet, L. Lancieri, and F. Depaepe, "Investigating the Effectiveness of Online Learning Environments for Complex Learning," The 9th International Conference on Learning Analytics \& Knowledge (LAK19), USA, 2019.

[4] S. Jafari and Z. Mollaei, "Mediating Role of Self-regulated Learning Strategies for Spiritual Intelligence and Academic Achievement," Iranian Journal of Medical Education, pp. 424-432, 2019.

[5] Hatami, R. Mahmoudi, D. H. Nia, M. R. Badrani, and M. S. Kamboo, "The Relationship between Spiritual Intelligence and Resilience with Self-efficacy of Clinical Performance in Nurses Working in Shoushtar Educational Hospitals," Journal of Research in Medical and Dental Science, pp. 8-13, 2019.

[6] R. Häusler and S. Bosse, "Analysis and Modeling of Learning Systems and Development of a Process Model for Flexible Orchestration of Learning Environments," Otto von Guericke University, Magdeburg, 2018.

[7] Shitikaa, R. Nayyar, A. Vij and S. Sanghi, "Sculpting role of Emotional and Spiritual Intelligence for Retention: A study of Higher Education System in India," International Journal of Information Systems \& Management Science, Vol. 2, No. 2, pp. 374-382, 2019.

[8] Ş. Gunduz, "The Relationship between Spiritual Leadership and Organizational Cynicism: The Moderating Effect of Emotional Intelligence," Doğuș Üniversitesi Dergisi, Istanbul, 2017.

[9] M. A. Anwar, A. M. O. Gani and M. S. Rahman, "Effects of spiritual intelligence from Islamic perspective on emotional intelligence," Journal of Islamic Accounting and Business Research, Vol. 11, No. 1, pp. 216-232, 2020.

[10] D. Mulcahy and C. Morrison, "Assembling 'innovative' learning environments: Affective practice and its politics," Journal Educational Philosophy and Theory, vol. 49, no. 8, pp. 749-758, 2017.

[11] S. Rajeswari and S. P. Selvam, "A Study on Students Academic Achievement in Relation to Emotional Intelligence and Spiritual Intelligence of M.Ed Students," International Journal of Arts, Science and Humanities, vol. 7, no. 1, pp. 24-41, 2019.

Correlating spiritual and emotional intelligence with academic performance among ... (Jamshid Ali Turi) 
[12] M. Mosavinezhad, M. Safara, S. Kasir and K. Minoo, "Role of Spiritual Intelligence and Personal Beliefs in Social Anxiety among University," Health, Spirituality and Medical Ethics Journal, Vol. 6, no. 3, pp. 11-17, 2018.

[13] L. C. Bland, "Applying Psychometric Theory to the Examination of Learning within Informal Engineering Learning Environments," George Mason University, Fairfax, 2017.

[14] B. Akbari, M. G. Azari and S. M. Mousavi, "The relationship between spiritual wellbeing and depression, stress, anxiety with cortisol level among nursing students," Researcher Bulletin of Medical Sciences, vol. 22, no. 1, pp. 252-268, 2017.

[15] F. Tizro-Toly, T. Mosazadeh and R. Kazemi, "The Effect Of Spiritual Intelligence Training On Adaptability, Accountability and Legislation Among 14-16 Year-Old Male Students," Salamat Ijtimai (Community Health), pp. 232-249, 2017.

[16] J. Whelan, "Teaching and Learning About Spirituality in Healthcare Practice Settings," Spirituality in Healthcare: Perspectives for Innovative Practice, vol. 3, no. 8, pp. 165-192, 2019.

[17] M. Farhan and O. Usman, "Effect Of Intellectual Intelligence, Intelligence Spiritual, Emotional Intelligence, and Behavior Study On The Level Of Understanding Of Students," Malaysian Journal of Education Management, vol. 3, no. 3, pp. 27-43, 2018.

[18] K. Shateri, A. A. Hayat, and H. Jayervand, "The Relationship Between Mental Health and Spiritual Intelligence Among Primary School Teachers," International Journal of School Health, vol. 3, no. 1, pp. 212-228, 2018.

[19] E. C. Fradelos, E. Kapsiocha, F. Tzavella, S. Kastanidou, K. Tsaras, D. Papagiannis, and I. V. Papathanasiou, "Factors Associated with Psychological Distress in University Students and the Relation to Emotional Intelligent and Spirituality: a Cross-sectional Study," Spirituality and Mental Health, vol. 31, no. 4, pp. 262-267, 2019.

[20] M. C. C. Jiang, Y. Brown, L. E. R. Double, K. S. B. Micaela, and M. Amirali, "Emotional intelligence predicts academic performance: A meta-analysis," Psychological Bulletin, vol. 146, no. 2, pp. 150-186, 2016.

[21] S. Aghajani and H. Samadifard, "Correlation of Spiritual Well-Being with Spiritual Intelligence and Emotional Intelligence in Students at Mohaghegh Ardebili University," Journal of Health Promotion Management, vol 3, no. 4, pp. 11-27, 2018.

[22] B. Suhaedir, Z. Siti, C. A. Duran, Indriwati and S. Endah, "The spiritual and social attitudes of students towards integrated problem based learning models," Issues in Educational Research, Vol. 28, No. 2, vol. 28, no. 2, pp. 254-270, 2018.

[23] M. Shamsi and N. Nastiezaie, "Evaluation of Mediating Role of Spiritual Intelligence in the Relationship between Social Capital and Psychological Capital of Graduate Students," Journal of Medical Education Development, vol. 11, no. 32, pp. 283-299, 2018.

[24] Singla and D. Kaur, "To Study The Role Of Spiritual Intelligence At Work Place: A Review," PIMT Journal of Research, Vol. 11, No. 2, pp. 90-95, 2019.

[25] M. Tajpour and A. Salamzadeh, "The effect of spiritual intelligence on organisational entrepreneurship: case study of educational departments in University of Tehran," Int. J. Management and Enterprise Development, Vol. 18, No. 3, pp. 205-219, 2019.

[26] M. A. A. Vinueza, The role of spirituality in building the resilience of migrant children in Central America. School of Social Science and Public Policy, London, 2016.

[27] F. Vasconcelos, "Spiritual intelligence: a theoretical synthesis and work-life potential linkages," International Journal of Organizational Analysis, Vol. 28, No. 1, pp. 109-134, 2019.

[28] E. Aydin, "The Effect of Spiritual Intelligence and Optimistic on Creativity in Team and Individual Sports Activities of Trabzon University Students," Asian Journal of Education and Training, vol. 5 no. 3, pp. 397-402, 2019.

[29] M. Matise, J. Ratcliff and F. Mosci, "A Working Model for the Integration of Spirituality in Counseling," Journal of Spirituality in Mental Health, vol. 20, no. 1, pp. 27-50, 2018.

[30] M. J. Al-Salkhi, "Spiritual Intelligence and Its Relation with Psychological Stability of a Sample of Students from the College of Arts and Sciences in the University of Petra," International Journal of Learning, Teaching and Educational Research, Vol. 18, No. 3, pp. 142-163, 2019.

[31] K. Martynowska and L. Zysberg, "Faith conquers all? Demographic and psychological resources and their associations with academic performance among religious college students," British Journal of Religious Education, vol 3, no. 6, pp. 291-307, 2017.

[32] M. A.Phillips and P. Ritala, "A complex adaptive systems agenda for ecosystem research methodology," Technological Forecasting and Social Change, Vol. 148, pp. 201-219, 2018.

[33] H. Adamson, "Substance Use, Abuse, and Treatment and their Correlation to Religiosity and Spirituality in a National Sample," The Chicago School of Professional Psychology, Chicago, 2017.

[34] B. Dobia and S. Roffey, "Respect for Culture-Social and Emotional Learning with Aboriginal and Torres Strait Islander Youth," Social and Emotional Learning in Australia and the Asia-Pacific, vol. 3, no. 5, pp. 313-334, 2017. 